\title{
Anti-Inflammatory Activity of Extracts of Leaves of Hygrophila spinosa T. Anders in Chronic Animal Models of Inflammation
}

\section{Arjun Patra $^{1 *}$, S. Jha ${ }^{2}$, P.N. Murthy ${ }^{3}$, Swaha Satpathy ${ }^{1}$}

${ }^{1}$ Institute of Pharmacy, Guru Ghasidas Vishwavidyalaya, Bilaspur-495 009, Chhattisgarh, India

${ }^{2}$ Birla Institute of Technology, Mesra-835 215, Ranchi, India

${ }^{3}$ Royal College of Pharmacy \& Health Sciences, Berhampur-760 002, Orissa, India

*Corresponding author: E-mail: arjun.patra@ rediffmail.com

\begin{abstract}
Hygrophila spinosa T. Anders (Acanthaceae) is traditionally used in Indian medicine for the treatment of microbial infections, liver diseases, cancer, inflammation, rheumatism, diabetes, pain, fever etc. The aim of the present study is to evaluate the anti-inflammatory activity of chloroform and alcoholic extracts of the leaves of $H$. spinosa in chronic inflammation models in rats as our previous study revealed that these two extracts had anti-inflammatory activity in carrageenan induced paw oedema model. Anti-inflammatory activity was evaluated by cotton pellet-induced granuloma and Freund's adjuvant-induced arthritis in rats. Antioxidant activity of the extracts was revealed by their scavenging activity of the stable 1,1-diphenyl-2picrylhydrazyl (DPPH) free radical and a flavonoid compound (apigenin) was also isolated and characterized from the alcoholic extract of the plant. Chloroform and alcoholic extracts showed anti-inflammatory activity both in cotton pellet-induced granuloma and Freund's adjuvant-induced arthritis in a dose dependent manner. The decrease in body weight due to injection of CFA was improved significantly by the above two extracts also. Both the extracts also exhibited antioxidant activity. The results demonstrated that H. spinosa has antiinflammatory activity in chronic models of inflammation which support the traditional use of $H$. spinosa in the treatment of rheumatism.
\end{abstract}

Keywords: Hygrophila spinosa, Cotton pellet-induced granuloma, Freund's adjuvant-induced arthritis 


\section{Introduction}

Hygrophila spinosa T. Anders (Acanthaceae) commonly known as 'Talmakhana' in Hindi is found in water-logged areas throughout India, contains a number of phytoconstituents viz. lupeol (Shailajan and Abhishek, 2008), $\beta$ - sitosterol (Tiwari et al., 1967), stigmasterol (Khare, 2007), ascorbic acid, $\beta$ - carotene (Sahoo and Acharya, 2005), nicotinic acid (Sharma et al., 2002), hentriacontane (Chopra et al., 1958), luteolin, luteolin-7-rutinoside (Balraj and Nagarajan, 1982), syringic acid, vannilic acid (Daniel, 2005) etc. In our earlier studies we have reported the other constituents, traditional uses, pharmacological activities of the plant (Patra et al., 2009a); various groups of phytoconstituents in petroleum ether, chloroform, alcoholic and aqueous extracts of the leaves of the plant (Patra et al., 2009b) and also few pharmacological studies of the above extracts (Patra et al., 2008, 2009c). The aim of this study was to determine the anti-inflammatory activity of chloroform and aqueous extracts of the leaves of $H$. spinosa in chronic inflammation models in rats.

\section{Materials and methods}

\subsection{Plant material}

H. spinosa plants were collected from Berhampur, Orissa, India and botanical identification was done through Department of Pharmaceutical Sciences, Birla Institute of Technology, Mesra, Ranchi (Voucher no. BITPcog. 463/07-08). Voucher specimen was preserved in the department for further verification.

\subsection{Preparation of different extracts}

The leaves were washed thoroughly, dried under shade and pulverized. The coarse powder was extracted successively with petroleum ether, chloroform and alcohol using soxhlet apparatus. The extracts were dried using a rotary vacuum evaporator and stored in a desiccator until further use.

\subsection{Cotton pellet-induced granuloma in rats}

Cotton pellet-induced granuloma in rats is used to screen drugs preventing transudative, exudative and proliferative components of chronic inflammation (Winter et al., 1957; Mizushima et al., 1972; Spector, 1969). Granuloma was induced by subcutaneous implant of a sterile cotton pellet $(50 \mathrm{mg})$ in the dorsal area of anaesthetized rats. One day after the implant, the animals were divided into six groups $(n=6)$ and were administered with vehicle/standard drug/test substances as mentioned in Table 1 for 10 days. On the $10^{\text {th }}$ day the pellets were dissected out, 
dried in an incubator at $60^{\circ} \mathrm{C}$ until a constant weight was obtained. The granuloma tissue formation (dry weight of granuloma) was calculated after deducting the weight of cotton pellet $(50 \mathrm{mg})$ from the constant dry weight of pellet and taken as a measure of granuloma tissue formation. The anti inflammatory effect was assessed by degree of inhibition of the granuloma weight in the groups under study as compared with the control. The granuloma inhibition percentage for each group was calculated by comparison with the control group considered as $100 \%$ of inflammatory activity.

\subsection{Freund's adjuvant-induced arthritis in rats}

Rats with an initial body weight of 150-200 gm are used in the study. On day 1, they are injected into the sub plantar region of the left hind paw with $0.1 \mathrm{ml}$ of complete Freund's adjuvant (CFA, Sigma) (Wei et al., 1986). Dosing with the test compounds or the standard is started on the same day and continued for 12 days. Paw volumes of both sides and body weight are recorded on the day of injection, whereby paw volume is measured plethysmographically. On day 5, the volume of the injected paw is measured again, indicating the primary lesion and the influence of therapeutic agents on this phase (Newbould, 1963). From day 13 to 21, the animals are not dosed with the test compound or the standard. The severity of the induced adjuvant disease is followed by measurement of the non injected paw (secondary lesions) with a plethysmometer (Walz et al., 1971). The body weight was recorded at a weekly interval upto 21 days. On day 21 , the severity of the secondary lesions is evaluated visually by observing redness/inflammation/nodules in hind paws, fore paws, ears, nose and tail (Vogel, 1997).

\subsection{Antioxidant activity}

Antioxidant activity of different extracts was measured on the basis of the scavenging activity of the stable 1, 1-diphenyl-2-picrylhydrazyl (DPPH) free radical (Burits and Bucar, 2000; Dasgupta and De, 2007 ). Various concentrations of the extracts were added to 0.004\% methanolic solution of DPPH. After $30 \mathrm{~min}$ the absorbance at $517 \mathrm{~nm}$ was determined, and the percentage inhibition activity was calculated using the following formula.

$\%$ inhibition $=[(\mathrm{Ac}-\mathrm{At}) / \mathrm{Ac}] \times 100$

Where, $\mathrm{Ac}=$ absorbance of control sample and At $=$ the absorbance of test sample.

2.6 Isolation of compound $\mathbf{1}$ from alcoholic extract

$50 \mathrm{gm}$ of alcoholic extract was column chromatographed on a silica gel column (mesh 60-120) and eluted with solvent mixtures of increasing polarity: chloroform (300 ml), 
chloroform-acetone $[(80: 20,300 \mathrm{ml}),(60: 40,300 \mathrm{ml}),(40: 60,300 \mathrm{ml}),(20: 80,300 \mathrm{ml})]$, acetone $(300 \mathrm{ml})$, acetone-methanol [(80:20, $300 \mathrm{ml}),(60: 40,300 \mathrm{ml}),(40: 60,300 \mathrm{ml}),(20: 80,300 \mathrm{ml})]$ and methanol $(300 \mathrm{ml})$. Fractions $(20 \mathrm{ml})$ were collected and monitored on TLC. Fractions (151 to 165 ) collected were pulled together as these fractions showed a single spot of same $\mathrm{R}_{\mathrm{f}}$ value in TLC. It was evaporated in a water bath $\left(70-80^{\circ} \mathrm{C}\right)$ to afford a solid residue. The residue was dissolved in EtOH with little warming on a water bath. It was left undisturbed in refrigerator when crystals of compound $\mathbf{1}$ was obtained (yield: $0.0015 \% \mathrm{w} / \mathrm{w}$ ).

\subsection{Characterization of compound 1}

The various instruments used for recording the data for compound $\mathbf{1}$ are: FTIR spectroscopy (Shimadzu, IRPrestige-21), elemental analysis (Elementar, Vario EL III), ${ }^{1} \mathrm{H}$ and

${ }^{13} \mathrm{C}$ NMR spectra (PABBO BB NMR spectrophotometer), mass spectroscopy etc. Other physicochemical characters as melting point, solubility and physical appearance were also recorded.

\subsection{Statistical analysis}

The results were expressed as mean \pm standard error mean (SEM). Statistical analysis of the data was carried out using one way analysis of variance (ANOVA) followed by Student's $\mathrm{t}$-test to determine the significant difference between the control and the treated groups. $\mathrm{P}<0.05$ was considered significant.

\section{Results}

\subsection{Cotton pellet-induced granuloma}

The percentage inhibition of granuloma formation by chloroform and alcoholic extract $(400 \mathrm{mg} / \mathrm{kg})$ were 24.09 and $35.69 \%$ respectively $(p<0.05)$ (Table 1$)$. Hence the decrease in granuloma weight indicated the anti-inflammatory activity of alcoholic and chloroform extracts of $H$. spinosa in the treatment related to various types of inflammatory disorders.

\subsection{Freund's adjuvant-induced arthritis}

Injection of complete Freund's adjuvant into the rat paw induces inflammation as primary lesion with a maximum after 3 to 5 days. Secondary lesions occur after a delay of approximately 11 to 12 days which are characterized by inflammation of non-injected sites (hind leg, forepaws, ears, nose and tail), a decrease of weight and immune responses. The decrease in body weight due to injection of CFA was improved significantly by chloroform and alcoholic extracts of H. spinosa (Fig. 1). Further, there was significant inhibition of oedema both after 5 days (only by 
alcoholic extract at $400 \mathrm{mg} / \mathrm{kg}$ dose) and 21 days (by both chloroform and alcoholic extract) of CFA administration (Table 2). The percentage inhibition of paw oedema by chloroform and alcoholic extract $(400 \mathrm{mg} / \mathrm{kg}$ ) after 21 days of CFA treatment was 22.72 and $29.54 \%$ respectively. Further, the extent of inhibition by both the extracts was more than the standard drug, indomethacin $(20.45 \%)$. The severity of secondary lesions was also decreased by both the above extracts. These findings confirm that the $H$. spinosa can be used for the treatment of chronic inflammation and arthritis.

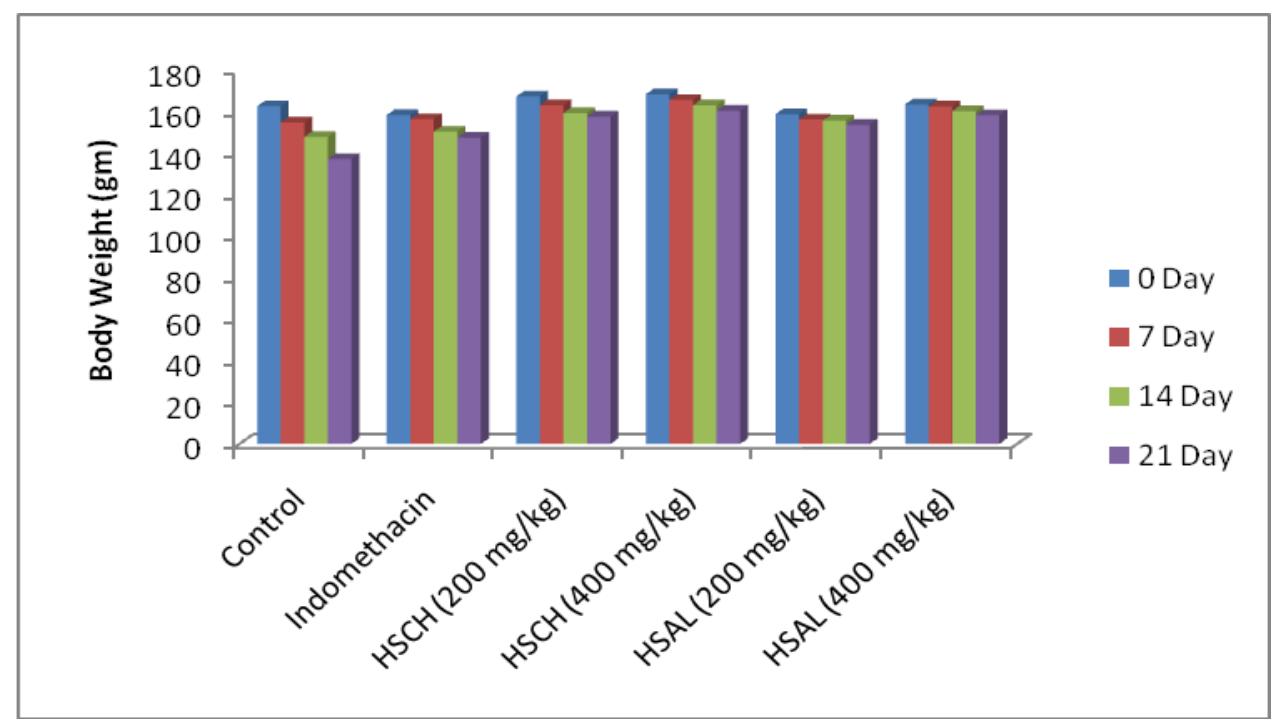

Fig. 1. Effect of different extracts of H. spinosa leaf on body weight of animals in CFA induced arthritic rats. $\mathrm{HSCH}$, chloroform extract; HSAL, alcoholic extract

Table 1. Effect of different extracts of $H$. spinosa leaf on cotton pellet-induced granuloma

\begin{tabular}{|c|c|c|c|}
\hline Treatment & $\begin{array}{c}\text { Dose } \\
(\mathrm{mg} / \mathrm{kg}, \text { p.o. })\end{array}$ & $\begin{array}{c}\text { Weight of dry } \\
\text { granuloma (mg) }\end{array}$ & $\begin{array}{c}\text { Percentage } \\
\text { inhibition of granuloma }\end{array}$ \\
\hline Vehicle (Control) & - & $122.36 \pm 2.32$ & - \\
\hline Indomethacin & 10 & $65.42 \pm 1.52^{*}$ & $46.53^{*}$ \\
\hline Chloroform & 200 & $109.65 \pm 1.05^{*}$ & $10.38^{*}$ \\
\cline { 2 - 4 } & 400 & $92.88 \pm 0.98^{*}$ & $24.09^{*}$ \\
\hline Alcoholic & 200 & $102.28 \pm 1.06^{*}$ & $16.41^{*}$ \\
\cline { 2 - 4 } & 400 & $78.68 \pm 0.86^{*}$ & $35.69^{*}$ \\
\hline
\end{tabular}

Values are expressed as mean \pm S.E.M. $(n=6) ;{ }^{*}<0.05$ vs. control. 
Table 2. Effect of different extracts of $H$. spinosa on adjuvant induced arthritis

\begin{tabular}{|c|c|c|c|c|c|}
\hline Treatment & \multirow{2}{*}{$\begin{array}{c}\text { Dose } \\
(\mathrm{mg} / \mathrm{kg})\end{array}$} & \multicolumn{2}{|l|}{ Increase in paw volume (in ml) } & \multicolumn{2}{l|}{ Percentage inhibition } \\
\cline { 3 - 6 } & & $\begin{array}{c}\text { After } \\
5 \text { days }\end{array}$ & $\begin{array}{c}\text { After } \\
21 \text { days }\end{array}$ & $\begin{array}{c}\text { After } \\
5 \text { days }\end{array}$ & $\begin{array}{c}\text { After } \\
21 \text { days }\end{array}$ \\
\hline Control & - & $0.56 \pm 0.02$ & $0.44 \pm 0.04$ & - & - \\
\hline Indomethacin & 10 & $0.54 \pm 0.02$ & $0.35 \pm 0.05^{*}$ & 3.57 & $20.45^{*}$ \\
\hline Chloroform & 200 & $0.54 \pm 0.02$ & $0.40 \pm 0.03$ & 3.57 & 9.09 \\
\cline { 2 - 6 } & 400 & $0.52 \pm 0.01$ & $0.34 \pm 0.02^{*}$ & 7.14 & $22.72^{*}$ \\
\hline Alcoholic & 200 & $0.53 \pm 0.02$ & $0.38 \pm 0.03^{*}$ & 5.35 & $13.63^{*}$ \\
\cline { 2 - 6 } & 400 & $0.50 \pm 0.02 *$ & $0.31 \pm 0.04^{*}$ & $10.71 *$ & $29.54^{*}$ \\
\hline
\end{tabular}

Values are expressed as mean \pm S.E.M. $(\mathrm{n}=6) ;{ }^{*} \mathrm{p}<0.05$ vs. control

\subsection{Antioxidant activity}

Both the extracts exhibited antioxidant activity in DPPH method and the potency of different extracts are in the following order: alcoholic>chloroform (Table 3).

Table 3. Free radical scavenging activity of different extracts of $H$. spinosa in DPPH method

\begin{tabular}{|c|c|c|}
\hline \multirow{2}{*}{$\begin{array}{c}\text { Concentration } \\
(\mu \mathrm{g} / \mathrm{ml})\end{array}$} & \multicolumn{2}{|c|}{ \% free radical scavenging } \\
\cline { 2 - 3 } & $\begin{array}{c}\text { Chloroform } \\
\text { Extract }\end{array}$ & $\begin{array}{c}\text { Alcoholic } \\
\text { Extract }\end{array}$ \\
\hline 25 & $10.36 \pm 0.69$ & $13.14 \pm 1.24$ \\
\hline 50 & $18.17 \pm 1.03$ & $20.80 \pm 0.75$ \\
\hline 100 & $24.83 \pm 0.78$ & $29.96 \pm 0.79$ \\
\hline 200 & $35.8 \pm 2.48$ & $41.17 \pm 1.58$ \\
\hline 400 & $49.81 \pm 4.42$ & $56.05 \pm 3.27$ \\
\hline
\end{tabular}

Values are mean \pm SEM $(n=3)$

Characterization of compound 1

5,7-Dihydroxy-2-(4-hydroxyphenyl)-4H-1-benzopyran-4-one (1) i.e., apigenin (Fig. 2) was isolated as whitish yellow crystals and its elemental composition was determined to be $\mathrm{C}_{15} \mathrm{H}_{10} \mathrm{O}_{5}$ (Anal. Calcd for $\mathrm{C}_{15} \mathrm{H}_{10} \mathrm{O}_{5}$ : C, 66.67; H, 3.73 and O, 29.60. Found: C, 66.55; H, 3.73 and O, 29.57). Melting point: $337-339^{\circ} \mathrm{C}$ and soluble in warm EtOH. It also contains hydroxyl (Lucas 
reagent), phenol $\left(\mathrm{FeCl}_{3}\right.$ test) and ketone (2,4-dinitrophenyl hydrazene) functional groups which was found from functional group analysis (Siddiqui and Ali, 1997; Nadendl, 2005) and supported by IR spectroscopy. Phytochemical analysis (Shinoda test) of the compound confirmed its flavonoid nature (Khandelwal, 2005). IR (KBr) $\mathrm{cm}^{-1}: 3312.54(\mathrm{OH}), 3064.46(\mathrm{CH})$, $2952.80(\mathrm{CH}), 1664.64(\mathrm{C}=\mathrm{O}), 1608.15(\mathrm{C}=\mathrm{C}), 1144.22(\mathrm{C}-\mathrm{O}-\mathrm{C})$ etc. UV $\lambda_{\max }(\mathrm{EtOH}): 336 \mathrm{~nm}$. MS m/z: $270\left(\mathrm{M}^{+}\right)\left(\right.$Calcd for $\mathrm{C}_{15} \mathrm{H}_{10} \mathrm{O}_{5}:$ 270.24), 242, 220, 152 and 120. NMR spectrum of this compound superimposed with the data published in previous studies (Ersoz et al., 2002; Fathiazad et al., 2006; Breitmaier and Voelter, 1989; Harborne and Mabry, 1982). The structure was simulated using ACD/NMR program (ACD/ChemSketch-Product Version: 10.00) to obtain the chemical shifts of both proton and carbon where the experimental data matched with the simulated data.

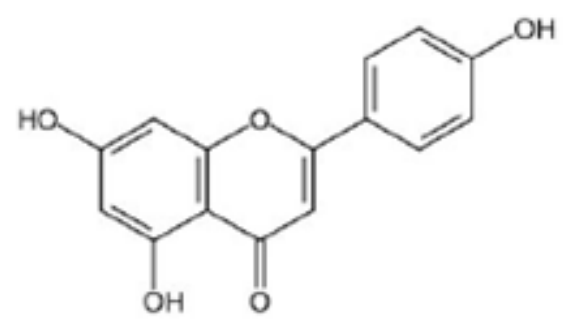

Fig. 2. Structure of compound 1

\section{Discussion}

The cotton pellet granuloma method has been widely employed to assess the transudative, exudative and proliferative components of chronic inflammation (Spector, 1969). The fluid absorbed by the pellet greatly influences the wet weight of the granuloma and the dry weight correlates well with the amount of granulomatous tissue formed (Swingle and Shideman, 1972). Monocyte infilteration and fibroblast proliferation rather than neutrophil infilteration and exudation take place in chronic inflammation (Dunne, 1990). Efficacy of anti-inflammatory agents in chronic inflammatory states is indicated by their ability to inhibit the increase in the number of fibroblasts during granular tissue formation (Gupta et al., 2003). We found a dosedependent inhibition of granuloma formation by chloroform and alcoholic extracts of $H$. spinosa leaf which reflected its efficacy to inhibit the proliferative phase of the inflammation process, i.e. increase in the number of fibroblasts and synthesis of collagen and mucopolysaccharides during granuloma tissue formation (Arrigoni-Martellie, 1977). 
Determination of paw volume and changes in body weight of the animals has been used in evaluating anti-inflammatory activity and therapeutic effects of the treatment. In the present study, it was found that the alcoholic and chloroform extracts showed significant antiarthritic effect evidenced by increase in body weight and decreased oedema. Prostaglandins greatly potentiate exudates by inducing relaxation of arteriolar smooth muscle and increasing the blood supply to the tissue (Williams, 1979). Further, Rheumatoid arthritis (RA) is a chronic, cytokinemediated destructive inflammatory polyarticular joint disease, characterized by massive synovial proliferation, systemic and local inflammation resulting in cartilage and bone destruction (Koch, 1998; McCoy et al., 2002). Prostaglandins are involved in a number of biologic activities relevant to the pathogenesis of RA, the pro-inflammatory aspects of this disease are also mediated by $\mathrm{PGE}_{2}$ (Dayer and Fenner, 1992; Lippiello et al., 1979; Davies et al., 1984). The ability of the extracts to reduce CFA induced arthritis may thus be related to its inhibitory action of prostaglandin synthesis.

Several anti-inflammatory, digestive, antinecrotic, neuroprotective and hepatoprotective drugs have recently been shown to have an antioxidant and/or radical-scavenging mechanism as part of their activity (Repetto and Llesuy, 2002). Free radicals are important mediators that provoke or sustain inflammatory processes and, consequently, their neutralisation by antioxidants and radical scavengers can attenuate inflammation (Geronikaki and Gavalas, 2006; Pedernera et al., 2006).

Several flavonoids isolated from medicinal plants have been discovered to possess significant anti-inflammatory effects (Duke, 1992). According to Oktay et al. (2003) a highly positive relationship between total phenolics and antioxidant activity appears to be the trend in many plants. The anti-inflammatory activity is a common property of many flavonoids, tannins and sterols (Goncalves et al., 2008; Singh et al., 1997; Vimala et al., 1997) and these phytoconstituents also possess antioxidant property (Oktay et al., 2003). The presence of the said constituents in the extracts of $H$. spinosa may be responsible for the observed activities.

In summary, our results suggest that $H$. spinosa has considerable potency in antiinflammatory action and has prominent effects on adjuvant-induced arthritis by alleviating paw edema. Hence, the results of the present study support the traditional use of $H$. spinosa in the treatment of rheumatism. 


\section{References}

1. Arrigoni-Martellie, E., 1977. Inflammation and Anti-inflammatory. Spectrum Publications, New York, pp. 110-120.

2. Balraj, P., Nagarajan, S., 1982. Apigenin 7-O-glucuronide from the flowers of Asteracantha longifolia Nees. Indian Drugs 19(4), 150-152.

3. Breitmaier, E., Voelter, W., 1989. Carbon-13 NMR Spectroscopy. VCH Verlagsgesellschaft MBH, New York, pp. 450-457.

4. Burits, M., Bucar, F., 2000. Antioxidant activity of Nigella sativa essential oil. Phytotherapy Research 14, 323-28.

5. Chopra, R.N., Chopra, I.C., Handa, K.L., Kapur, L.D., 1958. Indigenous Drugs of India. UN Dhur \& Sons Pvt. Ltd., Calcutta, pp. 353, 603, 665, 693.

6. Daniel, M., 2005. Medicinal Plants: Chemistry and Properties. Science Publishers, Texas, pp. 193.

7. Dasgupta, N., De, B., 2007. Antioxidant activity of some leafy vegetables of India: A comparative study. Food Chemistry 101, 471-474.

8. Davies, P., Bailey, P., Goldenberg, M., Ford-Hutchinson, A., 1984. The role of arachidonic acid oxygenation products in pain and inflammation. Annual Review of Immunology 2, 335-357.

9. Dayer, J.M., Fenner, H., 1992. The role of cytokines and their inhibitors in arthritis. Baillieres Clinical Rheumatology 6, 485-516.

10. Duke, J.A., 1992. Handbook of Biologically Active Phytochemicals and their Activities. CRC Press, Boca Raton, FL.

11. Dunne, M.W., 1990. Concepts of Altered Health States. Lippincott, Philadelphia, pp.165-176.

12. Ersoz, T., Harput, U.S., Saracoglu, I., Calis, I., 2002. Phenolic compounds from Scutellaria pontica. Turkish Journal of Chemistry 26, 581-588.

13. Fathiazad, F., Delazar, A., Amiri, A., Sarker, S.D., 2006. Extraction of flavonoids and quantification of rutin from waste Tobacco leaves. Iranian Journal of Pharmaceutical Research 3, 222-227. 
14. Geronikaki, A.A., Gavalas, A.M., 2006. Antioxidants and anti-inflammatory diseases: synthetic and natural antioxidants with anti-inflammatory activity. Comb. Chem. High Throughput Screening 9, 425-442.

15. Goncalves, J.C.R., Oliveira, F.D.S., Benedito, R.B., Sousa, D.P.D., Almeida, R.N.D., 2008. Antinociceptive activity of (-)-carvone: evidence of association with decreased peripheral nerve excitability. Biological \& Pharmaceutical Bulletin 31, 1017-1020.

16. Gupta, M., Mazumder, U., Ramanathan, S.K., Thangavel, S.K., 2003. Studies on antiinflammatory, analgesic and anti-pyretic properties of methanol extract of Caesalpinia bonducella leaves in experimental animal models. Iranian Journal of Pharmacology and Therapeutics 2, 30-34.

17. Harborne, J.B., Mabry, T.J., 1982. The Flavonoids: Advances in Research. Chapman and Hall Ltd., London.

18. Khandelwal, K.R., 2005. Practical Pharmacognosy. $14^{\text {th }}$ edition, Nirali Prakashan, Pune, pp. 146-155.

19. Khare, C.P., 2007. Indian Medicinal Plants- An Illustrative Dictionary. Springer-Verlag, Berlin Heidelburg, pp. 70-71.

20. Koch, A.E., 1998. Angiogenesis: implication of rheumatoid arthritis. Arthritis Rheumatism 41, 951-962.

21. Lippiello, L., Yamamoto, K., Robinson, D., Mankin, H.J., 1979. Involvement of prostaglandins from rheumatoid synovium in inhibition of articular cartilage metabolism. Arthritis Rheumatism 21, 909-917.

22. McCoy, J.M., Wicks, J.R., Audoly, L.P., 2002. The role of prostaglandin E2 receptors in the pathogenesis of rheumatoid arthritis. The Journal of Clinical Investigation 110, 651-658.

23. Mizushima, Y., Tsukada, W., Ankimoto, T.O., 1972. A modification of rat adjuvant arthritis for testing anti rheumatic drugs. Journal of Pharmacy and Pharmacology 24, 781785.

24. Nadendla, R.R., 2005. Principles of Pharmaceutical Organic Chemistry. Macmillan India Ltd.

25. Newbould, B.B., 1963. Chemotherapy and arthritis induced in rats by mycobacterium adjuvant. British Journal of Pharmacology 21, 127-136. 
26. Oktay, M., Gulcin, I., Kufrevioglu, O.I., 2003. Determination of in vitro antioxidant activity of fennel (Foeniculum vulgare) seed extract. Lebensmittel-Wissenschaft undTechnologie 36(2), 263-271.

27. Patra, A., Jha, S., Murthy, P.N., 2009a. Phytochemical and pharmacological potential of Hygrophila spinosa T. Anders. Phcognosy Review 3(6), 330-341.

28. Patra, A., Jha, S., Murthy, P.N., 2009b. Pharmacognostical standardization of leaves of Hygrophila spinosa T. Anders. Phcognosy Journal 1(2), 82-87.

29. Patra, A., Jha, S., Murthy, P.N., Aher, V.D., Chattopadhyay, P., Panigrahi, G., Roy, D., 2009c. Anti-inflammatory and antipyretic activities of Hygrophila spinosa T. Anders Leaves (Acanthaceae). Tropical Journal of Pharmaceutical Research 8(2), 133-137.

30. Patra, A., Jha, S., Murthy, P.N., Roy, D., Sahu, A.N., 2008. Analgesic and antimotility activities of leaves of Hygrophila spinosa T. Anders. Pharmacologyonline 2, 821-828.

31. Pedernera, A.M., Guardia, T., Guardia Calderon, C., Rotelli, A.E., de la Rocha, N.E., Di Genaro, S., Pelzer, L.E., 2006. Anti-ulcerogenic and anti-inflammatory activity of the methanolic extract of Larrea divaricata Cav. In rats. Journal of Ethnopharmacology 105, 415-420.

32. Repetto, M.G., Llesuy, S.F., 2002. Antioxidant properties of natural compounds used in popular medicine for gastric ulcers. Brazilian Journal of Medical and Biological Research $35,523-534$.

33. Sahoo, B., Acharya, P., 2005. Comparative studies on nutritional status of leafy vegetables. Crop Research (Hisar) 30(3), 406-408.

34. Shailajan, S., Abhishek, S., 2008. A comparative evaluation of phytochemical fingerprint of Asteracantha longifolia Nees. using HPTLC. Asian Journal of Plant Sciences 7(6), 611-614.

35. Sharma, P.C., Yelne, M.B., Dennis, T.J., 2002. Database on Medicinal Plants Used in Ayurveda. Vol. 4, Central Council for Reseach in Ayurveda and Siddha, New Delhi, pp. 320-331.

36. Siddiqui, A.A., Ali, M., 1997. Practical Pharmaceutical Chemistry. CBS Publishers \& Distributors, New Delhi.

37. Singh, S., Bani, S., Singh, G.B., Gupta, B.D., Banerjee, S.K., Singh, B., 1997. Antiinflammatory activity of lupeol. Fitoterapia 68, 9-16. 
38. Spector, W.G., 1969. The granulomatous inflammatory exudates. International Review of Experimental Pathology 8, 1-55.

39. Swingle, K.F., Shideman, F.E., 1972. Phases of the inflammatory response to subcutaneous implantation of a cotton pellet and their modification by certain antiinflammatory agents. Journal of Pharmacology and Experimental Therapeutics183, 226234.

40. Tiwari, R.D., Srivastava, K.C., Sattsangi, P.D., 1967. Examination of the fixed oil from the seeds of Hygrophila spinosa. Indian Journal of Applied Chemistry 30, 58-59.

41. Vimala, R., Nagarajan, S., Alam, M., Susan, T., Joy, S., 1997. Antiinflammatory and antipyretic activity of Michelia champaca Linn., (white variety), Ixora brachiata Roxb. and Rhynchosia cana (Willd.) D.C. flower extract. Indian Journal of Experimental Biology 35, 1310-1314.

42. Vogel, H.G., Vogel, W.H., 1997. Drug Discovery and Evaluation. Springer-verlag Berlin heidelberg New York, 368-371, 390-417.

43. Walz, D.T., Dimartino, M.J., Misher, A., 1971. Adjuvant-induced arthritis in rats. II. Drug effects on physiologic, and biochemical and immunologic parameters. Journal of Pharmacology and Experimental Therapeutics 178, 223-231.

44. Wei, W., Chen, M.Z., Xu, S.Y., 1986. Pharmacological effects of isoxicam. Chinese Pharmacological Bulletin 2, 29-34.

45. Williams, T.J., 1979. Prostaglandin $\mathrm{E}_{2}$, Prostaglandin $\mathrm{I} 2$ and the vascular changes of inflammation. British Journal of Pharmacology 65, 517-524.

46. Winter, C.A., Porter, C.C., 1957. Effect of alteration in side chain upon antiinflammatory and liver glycogen activity of hydrocortisone esters. Journal of American Pharmaceutical Association and Science 46, 515-519. 